\title{
Memórias e narrativas dos estudantes da educação do campo mediadas pelo caderno da realidade
}

\author{
Memories and narratives of rural education students \\ mediated by reality notebook
}

\section{Memorias y narrativas de estudiantes de la educación del campo mediados por el cuaderno de realidad}

\author{
JANINHA GERKE (iDa \\ AlessandRo da Silva Guimarães (iDb
}

\section{Resumo}

Este texto nasce no seio das experiências formativas empreendidas na Licenciatura em Educação do Campo, da Universidade Federal do Espírito Santo, no campus de Goiabeiras/Vitória, ES. Tem como objetivo dialogar com as memórias e narrativas dos sujeitos em formação, registradas nos Cadernos da Realidade, buscando à luz destas conhecer, reconhecer e compreender os processos enredados. Investiga como o uso desses cadernos tem potencializado as aprendizagens construídas nos territórios formativos do tempo universidade e do tempo comunidade. Fundamenta-se nos estudos de Walter Benjamin (1996), em especial nas discussões sobre experiência, e produz interlocuções teóricas com autores que caminham com o Movimento Nacional da Educação do Campo e a Formação por Alternância. Como perspectiva metodológica, analisa narrativas e memórias registradas nos Cadernos da Realidade a partir das discussões de Josso (2004) e Bertaux (2010). Compreende que os Cadernos podem ser empregados como mediações didático-pedagógicas da formação por alternância, capazes de propulsarem o pensar reflexivo e

\footnotetext{
a Universidade Federal do Espírito Santo, Vitória, ES, Brasil. Doutora em Educação, e-mail: professorajaninhaufes@gmail.com

b Universidade Federal do Espírito Santo, Vitória, ES, Brasil. Doutor em Educação, e-mail: alessandro2210@gmail.com
} 
problematizador da inserção comunitária dos estudantes, do desenvolvimento profissional docente no campo e, ainda, da própria trajetória dos sujeitos na licenciatura em Educação do Campo.

Palavras-chave: Licenciatura em Educação do Campo. Cadernos da Realidade. Memórias e narrativas. Profissão docente no campo.

\begin{abstract}
This text is born within the formative experiences undertaken in the Degree in Rural Education, from the Federal University of Espirito Santo, on the campus of Goiabeiras / Vitória, ES. It aims to dialogue with the memories and narratives of the subjects in training, registered in the Reality Notebooks, seeking in the light of these to know, recognize and understand the processes involved. It investigates how the use of these notebooks has enhanced the learning built in the formative territories of university and community time. It is based on the studies of Walter Benjamin (1996), especially in the discussions about experience, and produces theoretical interlocutions with authors who walk with the National Movement of Rural Education and Training by Alternation. As a methodological perspective, it analyzes narratives and memories recorded in Reality Notebooks from the discussions of Josso (2004) and Bertaux (2010). It understands that the Notebooks can be used as didactic-pedagogical mediations of alternating training, capable of promoting reflective and problematizing thinking of the community insertion of students, of the professional development of teachers in the field and, also, of the subjects' own trajectory in Rural Education.
\end{abstract}

Keywords: Degree in Rural Education. Reality Notebooks. Memories and narratives. Teaching profession in Rural Areas.

\title{
Resumen
}

Este texto surge de las experiencias formativas realizadas en el Grado en Educación Rural, de la Universidad Federal de Espírito Santo, en el campus de Goiabeiras / Vitória, ES. Su objetivo es dialogar con los recuerdos y las narrativas de los sujetos en formación, registrados en los Cuadernos de Realidad, buscando a la luz de estos para conocer, reconocer y comprender los procesos involucrados. Investiga cómo el uso de estos cuadernos ha mejorado el aprendizaje construido en los territorios formativos del tiempo universitario y comunitario. Se basa en los estudios de Walter Benjamin (1996), especialmente en las discusiones sobre la experiencia, y produce interlocuciones teóricas con autores que caminan con el Movimiento Nacional de Educación y Capacitación Rural por Alternancia. Como perspectiva metodológica, analiza narraciones y recuerdos registrados en Cuadernos de Realidad a partir de las discusiones de Josso (2004) y Bertaux (2010). Entiende que los Cuadernos pueden usarse como mediaciones didácticopedagógicas de la capacitación de la alternancia, capaces de promover el pensamiento 
reflexivo y problematizar la inserción comunitaria de los estudiantes, el desarrollo profesional de los docentes en el campo y, también, la propia trayectoria de los sujetos en Educación do Campo.

Palabras clave: Licenciatura en Educación Rural. Cuadernos de realidad. Memorias y narrativas. Profesión docente en el campo.

\section{Introdução}

O texto nasce no seio das experiências formativas empreendidas na Licenciatura em Educação do Campo, da Universidade Federal do Espírito Santo, campus Goiabeiras/Vitória, produzidas com os estudantes do $8^{\circ}$ período de Ciências Humanas e Sociais, durante o ano letivo de 2019. Com suas especificidades teóricopráticas e metodológicas pautadas na Formação por Alternância, a Licenciatura em Educação do Campo, organizada em tempo universidade e tempo comunidade, inaugura no âmbito da formação em nível superior o uso de novos e outros elementos ou mediações didático-pedagógicas que amalgamam o processo formativo, dentre esses o Caderno da Realidade. Nessa perspectiva, nossa pesquisa objetivou produzir um diálogo com as experiências, memórias e narrativas dos sujeitos em formação, registradas nos Cadernos da Realidade, buscando à luz dessas conhecer-reconhecer e compreender que processos são enredados e como o uso dos cadernos tem potencializado as aprendizagens construídas nos territórios formativos do tempo universidade e tempo comunidade, em diálogo ainda com as contribuições de Walter Benjamin sobre Experiência.

Como perspectiva metodológica, a pesquisa fez uso das histórias de vida que pensam um projeto (JOSSO, 2004) e histórias de práticas em situação (BERTAUX, 2010), elegendo assim a prática das narrativas registradas como experiências nos Cadernos, a partir do impulso "formação docente do campo", como mote reflexivo dessa discussão.

Desta forma, este artigo traz inicialmente uma contextualização do curso de licenciatura no contexto da Educação do Campo no Espírito Santo e o trabalho com os Cadernos da Realidade como uma mediação didático-pedagógica da Formação por Alternância. $\mathrm{Na}$ sequência, apresenta o pensamento Benjaminiano com diálogos de Experiência e suas contribuições na reflexão aqui enredada e, por fim, as memórias e 
narrativas como experiências narradas e registradas, propulsoras do pensar reflexivo e problematizador que coloca nas páginas do caderno e na roda dos diálogos as aprendizagens produzidas pelos sujeitos, estudantes da licenciatura, a partir de suas trajetórias no curso, inserção comunitária e desenvolvimento profissional docente no campo.

\section{A licenciatura em educação do campo no contexto da Universidade Federal do Espírito Santo}

A Licenciatura em Educação do Campo é ofertada atualmente por 44 universidades brasileiras, com habilitações em áreas do conhecimento, formando professores para atuarem nos anos finais do Ensino Fundamental, no Ensino Médio e na Educação de Jovens e Adultos. Foi criada a partir de demandas dos movimentos sociais do campo e da sociedade civil em geral, bem como do déficit formativo dos professores atuantes nas escolas do campo, contemplando assim os sistemas de ensino e as exigências legais para o trabalho docente.

Para a implantação, o Centro de Educação da Universidade Federal do Espírito Santo (Ufes) concorreu ao edital de seleção $n^{\circ}$ 12/2012SESU/SETEC/SECADI/MEC. Para isso, realizou um diagnóstico da formação de profissionais para a docência nos anos finais do Ensino Fundamental e Ensino Médio no Espírito Santo que apresentou, na ocasião, a existência de 1.324 escolas do campo de Educação Básica, sendo 162 da rede estadual, 1.146 da rede municipal e 16 Escolas Famílias Agrícolas (CEFFAs) vinculadas ao Movimento de Educação Promocional do Espírito Santo (Mepes), localizadas no perímetro rural capixaba. Contudo, ao se ancorar no Decreto $n^{\circ} 7.352 / 2010$, em seu Art. 1, \ $1^{\circ}$, Inciso II, que estabelece como escola do campo aquela situada em área rural, conforme definida pela Fundação Instituto Brasileiro de Geografia e Estatística (IBGE), ou situada em área urbana, desde que atenda predominantemente às populações camponesas, o número de instituições consideradas escolas do campo passou a corresponder a mais de $80 \%$ das escolas públicas do Espírito Santo (UFES, 2018).

Não obstante, no que se refere especificamente à formação docente, o diagnóstico revelou: 
[...] em 2012, atuavam 6.251 professores: 1.094 da rede estadual, 5.008 da rede municipal e 149 trabalhando nas EFAs. Cabe ressaltar que das 1.146 escolas municipais, 19 são Escolas Comunitárias Rurais - ECORs, em que atuam 204 professores. Nesse contexto, 5.831 professores são licenciados, porém, 23\% não possuem Licenciatura na sua área de atuação. Nas escolas localizadas em área de assentamento da Reforma Agrária, nas comunidades quilombolas e indígenas, mais de $40 \%$ dos professores são graduados em cursos de Pedagogia Plena, mas lecionam disciplinas da organização curricular dos anos finais do Ensino Fundamental. Desse modo, esses professores também necessitam de formação adequada à atuação nos anos finais do Ensino Fundamental e no Ensino Médio (UFES, 2018, p. 8).

Diante dessa realidade e, em conformidade com os critérios do edital em questão, a Ufes submeteu o projeto e foi contemplada para oferecer a Licenciatura em Educação do Campo nas seguintes habilitações: 1) Linguagens, Ciências Humanas e Sociais; 2) Ciências Naturais, nos campi de Goiabeiras e São Mateus respectivamente, atendendo atualmente 695 estudantes em 75\% dos municípios do estado. Cabe ressaltar que as habilitações dessa licenciatura transcendem a organização por disciplinas e habilitam o professor para atuar nas disciplinas de Arte, Língua Portuguesa e Educação Física (área de Linguagens); História, Geografia, Filosofia e Sociologia (área de Ciências Humanas e Sociais); Biologia, Física e Química (área de Ciências Naturais); e ainda na gestão e nos processos educativos escolares e comunitários.

Além disso, a Licenciatura em Educação do Campo encontra-se em conformidade com a Resolução MEC/CNE N 2 , de $1^{\circ}$ de julho de 2015, que institui as Diretrizes Curriculares Nacionais para a formação inicial em nível superior (cursos de licenciatura, cursos de formação pedagógica para graduados e cursos de segunda licenciatura) e para a formação continuada.

Como perspectiva teórico-prática e metodológica, o curso adota a Pedagogia da Alternância por constituir-se como possibilidade formativa dos sujeitos campesinos, com pressupostos vinculados aos princípios norteadores do Movimento Nacional da Educação do Campo. Nesse sentido, empreende um fazer que integra as espacialidades e temporalidades da universidade e da comunidade como territórios de formação do professor do campo, buscando, por meio das mediações pedagógicas construídas ao longo de 50 anos de experiência no Brasil, articular organicamente os saberes produzidos por diferentes sujeitos nos diversos espaços formativos. Nesse 
viés, a formação por alternância produzida na Licenciatura em Educação do Campo da Ufes buscou na experiência das Escolas Família Agrícola fertilizar seus fazeres, instituindo na formação em nível superior diálogos com saberes acumulados ao longo dos anos, além de adotar práticas que potencializam a aprendizagem em alternância, como o Caderno da Realidade.

Compreendemos que a formação por alternância cunhou ao longo de sua trajetória uma práxis inovadora, que se materializa por meio das mediações didáticopedagógicas (GERKE DE JESUS, 2011) como o Plano de Estudos, o Caderno da Realidade, as visitas e viagens de estudos, o projeto profissional do jovem, os estágios, entre outras, rompendo assim com os modelos convencionais de ensino e aprendizagem. Na esteira desse diálogo, a universidade se vê desafiada a transgredir velhos paradigmas e buscar nas experiências da formação por alternância da Educação Básica uma interlocução que não significa transposição de experiências, mas fertilização, no sentido de novas produções a partir do contexto da formação profissional docente do campo em nível superior.

Para tanto, o Caderno da Realidade, como mediação da formação por alternância, ocupa lugar fulcral, oferecendo aos docentes e aos sujeitos em formação possibilidades para se construir trajetórias, registrar memórias, narrativas e sínteses que refletem o percurso, com incertezas e contradições próprias do fazer humano. Mas, o que é então o Caderno da Realidade? Que produções tem provocado nos processos formativos da Licenciatura em Educação do Campo?

\section{O caderno da realidade}

Em nossas itinerâncias de trabalho e pesquisa, encontramos documentos que compõem o acervo da Pedagogia da Alternância no Brasil, localizado no Centro de Formação e Reflexão do Mepes no Espírito Santo, como também produzimos diálogos significativos com os sujeitos históricos que contribuíram na construção da Formação por Alternância em terras brasileiras.

Nessa perspectiva, ao tratar do Caderno da Realidade, afirmamos que as informações históricas aqui registradas nasceram dessa interlocução e encontraram 
nas páginas da escrita o espaço para a narrativa de uma história que nos interroga acerca dos diferentes usos do Caderno da Realidade como mediação formativa, inicialmente de jovens na Educação Básica e atualmente na Licenciatura em Educação do Campo.

Nesse sentido, documentos nos revelam que o Caderno da Realidade, conhecido na França como cabier d'exploitation familiale, surgiu na década de 1940 precipuamente como La monographie de village, cujo principal objetivo era promover uma incursão dos jovens estudantes nos aspectos históricos, culturais e sociais de sua comunidade. Posteriormente, pelo interesse apresentado em demasia às questões relativas ao desenvolvimento profissional na propriedade familiar, o Caderno passou a ser denominado como La monographie de l'exploitation familiale, com uma dimensão voltada ao trabalho da família na propriedade (ZAMBERLAN, 1989).

No Brasil, essa apropriação se deu na década de 1980 a partir do trabalho desenvolvido pelos monitores-professores italianos Sérgio Zamberlan e Mário Zulianni, ambos atuantes na implantação da Pedagogia da Alternância, por meio do trabalho das Escolas Família Agrícola, do Movimento de Educação Promocional do Espírito Santo. Em entrevista, nos narra Sérgio Zamberlan:

\begin{abstract}
Iniciamos aqui com o caderno da propriedade, mas passado o tempo vimos a necessidade de mudar, pois os estudantes que estavam nas escolas família agrícola não eram mais apenas filhos de pequenos proprietários como na década de 70 . Estavam mudando! Chegavam os meeiros e diaristas e depois até de outras profissões. E aí nos perguntamos: - vamos continuar com o nome caderno da propriedade se havia já um número mais de $30 \%$ de jovens que não têm terra? Ai pensamos bem! Estavam eu, Leaci, Cleber e Mário e pensamos num nome mais nosso, caderno da realidade, isso foi em 1982, daí em diante ficou conhecido até hoje como caderno da Realidade. Estudamos ainda Paulo Freire. Por que da Realidade? Porque a realidade é muito mais ampla do que a propriedade de um estudante (ZAMBERLAN, 2019).
\end{abstract}

A busca por um nome que abrangesse, além do aspecto territorial da propriedade familiar, a diversidade social e econômica dos estudantes que ingressavam nas EFAs, pôs em cena a dimensão integrativa da Formação por Alternância e sua capacidade criativa de uso do Caderno, ampliando-o como mediação que se propõe a pensar uma cartografia de família, terra, trabalho, comunidade, município, país e mundo não fragmentados e apartados, mas integrados. 
Compreendemos, a partir do diálogo com Sérgio, que a escolha do termo Caderno da Realidade tem raízes no pensamento freiriano, uma vez que sua obra integrou os estudos da equipe do centro de formação do Mepes e promoveu problematizações teóricas e metodológicas dos saberes e fazeres da Formação por Alternância naquele momento histórico.

Com o passar dos anos, apreendemos do uso do Caderno da Realidade, segundo Gimonet (2007), os efeitos da articulação dos espaços e tempos da formação por alternância: a exploração, a descoberta do meio de vida familiar, profissional e social do jovem; as relações, encontros e diálogos entre sujeitos e suas realidades; a expressão do pensamento oral e escrito. Portanto, o Caderno da Realidade tem como ponto de partida a concretude da vida do estudante e a transcende. Ele assume um percurso investigativo, dialógico e problematizador ao longo da formação do acadêmico, permitindo um olhar em retrocesso da sistematização produzida, um revisitar e um pensar histórico das relações humanas e seus contextos de vida.

$\mathrm{Na}$ Licenciatura em Educação do Campo, o Caderno da Realidade foi adotado desde a primeira turma, em 2014, e tem produzido provocações que emergem como locus do pensar acerca de suas contribuições na produção do registro de memórias e narrativas que impulsionam os processos formativos da docência. Os estudantes usam o Caderno da Realidade como mediação das investigações produzidas no âmbito de suas comunidades-escolas e nos diálogos teórico-práticos que emergem com os Planos de Estudo. Para nós, o Caderno da Realidade na Licenciatura em Educação do Campo é uma mediação didático-pedagógica da formação por alternância que reúne reflexões não esgotáveis no registro, mas que nascem deste para ocuparem debates sobre diferentes questões atravessadoras da formação docente, entre elas a experiência narrada e a dialogicidade. Portanto, o Caderno da Realidade é locus da memória, onde registramos o que não queremos esquecer; locus do memorial de nossas histórias de vida; locus de reflexões, pois podemos revisitá-las e, a partir da leitura, tecer outras produções. É também locus da pergunta; das narrativas da trajetória formativa; do outro; da vida cotidiana.... é lugar de muitos lugares! 


\section{Experiência e narrativa em Walter Benjamin}

$\mathrm{Na}$ esteira do pensar as memórias e experiências dos estudantes da Licenciatura em Educação do Campo, registradas nos Cadernos da Realidade, buscamos no diálogo com Walter Benjamin uma interlocução acerca da valorização das narrativas dos sujeitos, compreendendo-as não como restritas à oralidade, mas estendidas ao narrado escrito. Nesse sentido, o filósofo alemão é hoje uma referência quanto ao conceito de experiência e nos propicia uma ampla análise sobre a importância da narrativa na vida de todos nós. Benjamin foi um grande explorador da alma humana. Dotado de profunda sensibilidade e perspicácia, mergulhou em temas pouco corriqueiros e convencionais para sua época. Tal como nos faz perceber Riaviz (2001), os próprios títulos que Benjamin utilizou para nomear suas obras — "Pequena história da fotografia", "Livros infantis antigos e esquecidos", "História cultural do brinquedo" - nos sinalizam seu interesse por questões até pouco exploradas, tidas como diminutas em sua época. Exatamente por isso, ao discorrer suas teses em relação à história, Benjamin privilegia o cronista em detrimento do historiador clássico, sendo esse último, de algum modo, fruto dos métodos da própria ciência moderna, baseando-se em um sistema global, racional e generalizante de explicação e interpretação. No famoso texto intitulado "O narrador, considerações sobre a obra de Nikolai Leskov" (1996), Benjamin, antes de tudo, denuncia a morte do narrador, um reflexo da vida moderna. Já no primeiro parágrafo, ele sustenta que: "Por mais familiar que seja seu nome, o narrador não está de fato entre nós, em sua atualidade viva. Ele é algo distante, e que se distancia ainda mais" (BENJAMIN, 1996, p. 197).

Para compreendermos um pouco mais o interesse de Walter Benjamin sobre as narrativas, é importante entendermos o sombrio período pós primeira guerra mundial no qual esse pensador viveu, no início do século XX. Konder (1999), um dos estudiosos de Benjamin no Brasil, aponta que a primeira grande guerra mundial não apenas provocou mortes e mutilações físicas; mutilou também a experiência humana, produzindo silêncio e dor por parte dos combatentes que dela participaram. Como explicita Konder:

O predomínio dos valores da informação, com sua fugacidade, com sua secura, contribuiu para sancionar a atrofia, entre nós, da faculdade de nos comunicarmos, 
reciprocamente, nossas experiências. A guerra europeia de 1914-18 confirmou em Benjamin essa sua impressão: os soldados que tinham visto tantos horrores no front voltaram taciturnos para casa. No final da guerra, observou-se que os combatentes voltavam mudos do campo de batalha; não voltavam mais ricos e sim mais pobres de experiências a serem comunicadas (KONDER, 1999, p. 82).

Konder (1999) esclarece que nessa conjuntura se anunciava no pós-guerra: "[...] O novo quadro estava se impondo, irreversivelmente. Benjamin anunciava: 'O lado épico da verdade está morrendo'. Um novo modo de sentir estava prevalecendo.” (KONDER, 1999, p. 83). A fim de elucidar o declínio da narrativa no devastado mundo moderno, Benjamin usava duas expressões da língua alemã que, na verdade, distinguiam duas modalidades de conhecimento no universo humano: Erfabrung e Erlebnis. A primeira, Erfahrung, estaria relacionada a um saber "[...] obtido através de uma experiência que se acumula, que se prolonga, que se desdobra, como numa viagem (e viajar, em alemão, é efahren); o sujeito integrado numa comunidade dispõe de critérios que lhe permitem ir sedimentando as coisas, com o tempo" (KONDER, 1999, p. 83). Já a expressão “Erlebnis" remeteria ao sentido de uma experiência do sujeito isolado, sozinho, privado. Konder (1999) salienta ainda que "Erfahrung é o produto do trabalho" - esquematizaria Benjamin no Trabalho das passagens — "e Erlebnise, a fantasmagoria do ocioso". Não podemos deixar de reconhecer que, nas condições atuais, vivemos com intensidade, sob o signo da "Erlebnis" (KONDER, 1999, p. 83). Nessa perspectiva, e numa sociedade em que impera um individualismo crescente, falar da experiência dos sujeitos em conexão com outros talvez possa ser mais revolucionário do que imaginamos. Num contexto de processo formativo no campo educacional isso certamente tem uma relevância significativa.

Sob esse entendimento, torna-se impossível dissociarmos a produção da narrativa e os movimentos vividos que produzem as experiências dos sujeitos. No universo pós-moderno, a velocidade e a simultaneidade de informações e acontecimentos crescem numa ordem exponencial, sem que de fato possamos, muitas vezes, sequer nos conectar às pessoas e às experiências a nossa volta. Nesse contexto, o homem sente cada vez mais distante de si a experiência coletiva (Erfahrung), fazendo do espaço de diálogo com o outro — e, por conseguinte, consigo mesmo — um lugar vazio, instaurado pela imediaticidade, pelo pragmatismo utilitário e pela solidão 
constante que o ameaça enquanto um ser que é sendo com o outro. Desse modo, isolados e tantas vezes incapazes de compartilhar experiências com aqueles que os cercam, produzimos sujeitos silenciados e silenciosos.

Num quadro humanitário tão dramático vivido em outra época, percebemos a magnitude de um trabalho como o de Walter Benjamin. Afinal, mais do que meras fábulas, as narrativas expressam o intercâmbio de experiências entre sujeitos de uma comunidade. Ela está ligada a seu ethos, a uma hermenêutica do pertencimento, tendo em vista toda dimensão axiológica que perpassa as relações que o narrador estabelece com os outros, já que as narrativas se constituem como fontes de sentido e compreensão para uma dada realidade. Benjamin nos descortina que as pessoas nascidas na sociedade industrial moderna estão cada vez menos trocando experiências e, consequentemente, calando-se diante das experiências promovidas pelo próprio movimento da vida, tendo em vista que:

Se 'dar conselhos' parece hoje algo de inadequado, é porque as experiências estão deixando de ser comunicáveis. Em consequência, não podemos dar conselhos nem a nós mesmos nem aos outros. Aconselhar é menos responder a uma pergunta que fazer uma sugestão sobre a continuação de uma história que está sedo narrada. Para obter essa sugestão, é necessário primeiro saber narrar a história (sem contar que um homem só é receptivo a um conselho na medida em que verbaliza sua situação) (BENJAMIN, 1996, p. 200).

Nesse prisma, atento ao que foi negligenciado e excluído pela historiografia clássica, Riaviz (2001) nos influi a compreender que:

[...] para compreender o presente, o historiador deve constituir uma experiência (Erfahrung) com o passado, permitindo que o que foi esquecido possa surgir de novo, sendo retomado no presente. Os objetos congelados, petrificados no passado, saltam do contínuo histórico, interrompendo a linha do tempo para serem ressignificados. Assim, um álbum de retratos, um ornamento, uma porcelana, podem ser reinseridos numa cadeia de relações e acontecimentos, e aquilo que se havia tornado um fóssil pode novamente ganhar vida, renascendo para a história (RIAVIZ, 2001, p. 30).

Uma das razões para o declínio da narrativa e da memória na modernidade é a própria negação da morte, que se tornou algo cada vez mais comum na vida cotidiana moderna. Se por um lado, como Benjamin afirma, é da morte que deriva a autoridade do narrador (pois é a partir dela que as histórias e trajetórias dos antigos serão 
(re)contadas e ressignificadas por outras gerações), por outro, vivemos na cultura burguesa um pavor e um distanciamento cada vez maior daqueles que se foram e, consequentemente, da própria morte. Como explica Benjamin:

Hoje, os burgueses vivem em espaços depurados de qualquer morte e, quando chegar sua hora, serão depositados por seus herdeiros em sanatórios e hospitais. Ora, é no momento da morte que o saber e a sabedoria do homem e sobretudo sua existência vivida - e é dessa substância que são feitas as histórias - assumem pela primeira vez uma forma transmissível [...] A morte é a sanção de tudo o que o narrador pode contar. É da morte que deriva sua autoridade (BENJAMIN, 1996, p. 207-208).

Segundo Gagnebin (1999), se Benjamim resiste “[...] à tentação sedutora de afirmar, agora e imediatamente, a presença utópica e consoladora da salvação, é porque o desafio é de grande importância” (p. 64). Trata-se de repensar a própria relação com a morte e a finitude — sendo essas peças fundamentais na engrenagem da produção daquilo que chamamos de uma hermenêutica da memória, ou seja, da narrativa. Ao discorrer sobre Marcel Proust, famoso escritor Frances do século XIX que influenciou profundamente as ideias de Benjamin, Gagnebin (1999) nos provoca com a seguinte afirmação:

[...] Não é, portanto, porque Proust se lembra que ele conta, mas porque ele só se lembra no mais profundo do esquecimento. Benjamin ressalta que a 'memória involuntária' é mais próxima do esquecimento que da memória e que, 'no tecido do lembrar, no trabalho de Penélope da rememoração", o que transparece, o que também volta à superfície da narrativa são os 'ornamentos do olvido" (GAGNEBIN, 1999, p. 71).

A própria estilística impressa por Benjamin em seus escritos traduz de algum modo sua noção de memória e de história. O autor escreveu sobretudo na forma de ensaios. O seu próprio fazer já dava pistas de seu método: um pensamento que se recusava a pensar na forma linear tradicional — início-meio-fim — ou mesmo na crença ingênua, muito em voga por vários pensadores na época (até mesmo entre os pensadores do materialismo histórico que também o influenciaram) de que a história se constituía a partir da noção de progresso. Nele há uma produção que se materializou como um caminho aberto: nada definitivo, nada parado, mas numa dinâmica de inter-relações. De acordo com Helena (2003), “[...] A presença desse 
ruminar constante faz com que, na forma ensaística benjaminiana, o diverso se articule num outro tipo de prosa, a do tratado, cuja ordenação tem luz e organização muito próprias" (HELENA, 2003, p. 14-15). Segundo essa pesquisadora, o objetivo de Benjamin, ao se colocar nesse movimento, não seria o de arrebatar ou entusiasmar o leitor, mas o de induzir o leitor a pensar como quem escreve, fazendo-o parar e recomeçar, para que assim se instaure o próprio processo de reflexão, que carrega consigo de alguma forma o sentido de inacabamento. Um exemplo desse movimento produzido no pensamento Benjaminiano está presente em "Teses sobre o conceito de história", que datam do ano de 1940, obra na qual ele aponta os indícios para uma concepção que explicitamente rompe qualquer padrão evolucionista, linear e hierarquizante da história, tão em voga em seu tempo, antevendo aí, entre outros aspectos, uma narrativa fluída e aberta às perspectivas e experiências dos diferentes sujeitos, numa história que se julga e se reinventa a cada momento. Como nos ele expressa na tese de número 03 :

O cronista que narra os acontecimentos, sem distinguir entre os grandes e os pequenos, leva em conta a verdade de que nada do que um dia aconteceu pode ser considerado perdido para a história. Sem dúvida, somente a humanidade redimida poderá apropriar-se totalmente do seu passado. Isso quer dizer: somente para a humanidade redimida o passado é citável, em cada um dos seus momentos. Cada momento vivido transforma-se numa citation à l'ordre du jour - e esse dia é justamente o do juízo final (BENJAMIN, 1996, p. 223).

Portanto, tal como Benjamin nos provoca a pensar, podemos refletir que a própria história da educação do campo é continuamente transpassada e reescrita a partir das experiências dos sujeitos que a compõem e, certamente, as experiências narradas pelos estudantes do curso nos provocam a pensar nosso próprio processo formativo na condição de educadores do-no campo.

\section{Memórias e narrativas como experiência de formação docente do campo}

As narrativas transcritas a seguir nasceram do diálogo com os estudantes do oitavo período da Licenciatura em Educação do Campo, no ano 2019. São compreendidas à luz de Josso (2002) como histórias de vida que pensam um projeto, e 
Bertaux (2010), como histórias de práticas em situação. Nesse sentido, diferenciam-se da perspectiva teórica e metodológica das histórias autobiográficas que elegem todo o percurso de vida e profissão dos sujeitos.

[...] as histórias de vida postas ao serviço de um projeto são necessariamente adaptadas à perspectiva definida pelo projeto no qual elas se inserem, enquanto que as histórias de vida, no verdadeiro sentido do termo, abarcam a globalidade da vida em todos os aspectos, em todas as suas dimensões passadas, presentes e na sua dinâmica própria (JOSSO, 2004, p. 31).

Sob essa perspectiva, as narrativas ocorreram em uma roda de conversa com a apresentação dos registros das memórias nos cadernos da realidade, tendo como mote um itinerário temático que compõe as histórias de vida dos sujeitos. Os estudantes trouxeram para o círculo uma escrita que ganhou a sonoridade das vozes de suas trajetórias no curso, inserção comunitária e compromisso social, bem como as aprendizagens para a atuação profissional docente no campo. São essas três perspectivas que atravessam a reflexão proposta neste texto; não determinadas por nós, mas anunciadas pelos narradores. Para preservar a identidade dos sujeitos, foram atribuídos a eles nomes fictícios.

Em meio à escuta das histórias registradas nos cadernos da realidade, e sempre na companhia dos narradores (BENJAMIN, 1996), identificamos experiências significativas que nos conduziram à difícil tarefa da escolha. Portanto, num grupo heterogêneo quanto a cultura, gênero, cor, territórios de vida e trabalho, idade, entre outros, buscamos ouvir uma multiplicidade de vozes que pudessem traduzir essa pluralidade. E assim, iniciamos pela inserção e trajetória dos estudantes-narradores no curso de Licenciatura em Educação do Campo:

Ao entrar na Ufes desvendei um mundo bem grande, de várias pessoas com histórias fantásticas, de lutas, conquistas, passado e realidade. No curso Educação do Campo os olhos são mais voltados para as problemáticas e a realidade política, na área mais pobre, na comunidade pobre! Em cada momento ouvimos histórias lindas, porém cada indivíduo dessas tem um passado onde foram negadas várias políticas públicas (FREDERICO).

O ingresso de nossos estudantes à universidade é um marco na vida do ser campesino. Um sonho distante que se torna realidade, por meio da luta dos 
expropriados do saber acadêmico e que se materializa com a chegada a cada ano de novas turmas. A experiência do acesso à universidade pública emerge nas narrativas como o desvendar de um novo mundo, uma grande conquista e o reconhecimento dos direitos negados aos povos do campo. Nessa direção, as memórias surgem do Caderno da Realidade não como histórias nostálgicas de um passado, mas como trajetória vivida e, por isso, narradas como experiências que legitimam a inserção dos povos campesinos no espaço da universidade pública e gratuita. Trazer para a roda essa memória é reconhecer que há uma caminhada que antecede a entrada do narrador a esse espaço formativo e que, ao se beneficiar da conquista, faz jus ao registro escrito desse dessa narrativa histórica.

Não obstante, as agruras do processo formativo também se presentificam nas narrativas como aprendizagens produzidas em meio às experiências do estudo e do trabalho, no desafio cotidiano da conciliação entre ambos. Atravessar esse itinerário foi considerado pelos sujeitos-narradores uma conquista.

Na minha trajetória percorrida pela Ufes adquiri nesses 3 anos e meio muito conhecimento e uma extensa aprendizagem. A cada aula fiz novas descobertas e cada trabalho pude abrir a mente e por mais que a correria do dia-a-dia pudesse querer atrapalhar meus planos, no final era gratificante (ESTER).

Logo no começo do curso, a vontade maior era de voltar pelo mesmo caminho em que vim e seguir para meu berço, não me senti satisfeito e capaz de me manter no curso [...] No decorrer desse processo, apesar das dificuldades, consegui manter firmeza e pouco a pouco fomos dando sequência aos nossos estudos que nos fez perceber de fato a importância de lutarmos por uma vida melhor e uma sociedade mais digna a todos (JOÃO).

No registro que relata o desejo de se retornar ao lugar seguro, a experiência narrada também é de superação. Nessa perspectiva, a narrativa põe em cena a autoavaliação do sujeito-narrador em relação a sua capacidade de permanência no curso, sinalizando que o deslocamento se faz necessário. A entrada na universidade não implica apenas a chegada dos estudantes campesinos à cidade grande para ocupação do território do saber, mas pressupõe o deslocamento do pensar, do encontro com as diferenças, do fazer coletivo e da renúncia do lugar seguro. Portanto, pensar essa trajetória e registrá-la nas linhas do Caderno da Realidade é um 
movimento de conhecimento de si (JOSSO, 2004), que se faz no apreender das complexas imbricações que figuram nossa existência, dentre elas o deslocamento.

[...] A negação do direito à educação aos povos do campo é uma questão histórica e cultural. Para estarmos aqui foi necessário realizar um movimento contrahegemônico e derrubar algumas barreiras que impediam o nosso acesso e permanência na universidade. Sendo assim, minha visão sobre a oportunidade de ingresso aqui como aluno mudou, pois com as políticas de valorização do sujeito campesino e o surgimento de oportunidades para os mesmos possibilitou nossa ocupação nesse espaço como sujeitos de direito (JOÃO).

Como descrito nas páginas iniciais deste texto, a Licenciatura em Educação do Campo inaugura no Ensino Superior outros espaços e tempos formativos, por meio da Pedagogia da Alternância. Nesse sentido, o tempo comunidade é paritariamente ao tempo universidade locus de formação. Para além, a comunidade dos estudantes é espaço e tempo de investigação com vistas à transformação. Há, portanto, uma inserção comunitária dos estudantes com compromisso social e, nessa perspectiva, as experiências narradas e registradas no Caderno da Realidade introduzem elementos que tendem a fertilizar as discussões acadêmicas e seus aprofundamentos teóricos em diálogo com as realidades campesinas.

A questão social foi extremamente trabalhada junto com a construção do Caderno da Realidade. A minha chegada à primeira escola do campo [...] foi uma das coisas que mais me marcaram até hoje como estudante desse curso, pois foi a partir daí que começou em mim uma transformação que jamais terá fim, que é a de um indivíduo com maior senso crítico e menos certezas, com mais dúvidas do que afirmações, principalmente em relações às pessoas diferentes do meu convívio social (SANDRA).

Ao encontro do narrado, compreendemos que o debate acerca das questões sociais e a centralidade da comunidade na formação produz-se em interface à formação crítica dos campesinos. A chegada à escola pública com essa perspectiva configura um marco na vida do estudante que, como tal, acumula indubitavelmente outras experiências educativas com a escola básica. Contudo, pela via do trabalho com as questões sociais, o deslocar-se até a escola imbui-se de um novo olhar, pois está atrelado ao compromisso da Educação do Campo com a construção de uma outra escola. Nessa lógica, em diálogo com Antunes-Rocha et al. (2010), compreendemos 
que a gênese da Educação do Campo brotou da necessidade de transformar a escola pública existente no campo e, nessa perspectiva, ela se constitui em práxis. Além disso, essa gênese também nasceu da necessidade de modificar as relações sociais e de poder que marcam o campo brasileiro. Ela é fruto da denúncia de processos de exclusão da terra, educação, moradia, cultura e vida.

Destacamos ainda que as narrativas apontam para a possibilidade de confrontarmos a perversidade e as contradições do presente sem, com isso, convergirmos para uma visão fatalista da própria história. Pelo contrário, as falas dos estudantes indicam a possibilidade de se produzir uma história que já "relampeja" nas experiências de desconstrução e reconstrução de visão de mundo emergidas no processo formativo desses sujeitos ao longo da licenciatura. Afinal, como Benjamin nos provoca a pensar, a história é marcada por rupturas que motivam sempre a possibilidade de ter sido e de ser diferente. Como declara Konder (1999):

\begin{abstract}
A história, tal como os homens a fazem, não é um movimento contínuo, linear: ela é marcada por rupturas e se realiza através de lances que, em princípio, poderiam sempre ter sido diferentes. Isso não significa que a história seja absurda, que ela não fará sentido algum: significa apenas que seu sentido vem da ação dos homens e não pode ser pensado como se estivesse inteiramente dado antes de os sujeitos humanos agirem, isto é, antes de eles fazerem suas escolhas e tomarem suas decisões. O que tem acontecido até hoje não predetermina o que vai acontecer amanhã. O sujeito dispõe da possibilidade de surpreender. E o sujeito revolucionário precisa se empenhar no aproveitamento dessa possibilidade, para se contrapor não só ao quadro institucionalizado como ao movimento que resultou na institucionalização. Por ter plena consciência desse imperativo é que Benjamin exige do marxista que este trate sempre de "escovar a história a contrapelo" [...] (KONDER, 1999, p. 14).
\end{abstract}

A própria noção de "escovar a história a contrapelo" carrega consigo o desafio de assumir essas narrativas como um convite contínuo de questionar, repensar e ressignificar o que é institucionalizado, quando percebido em suas contradições e como fenômeno que, sendo uma construção histórica e social, pode ser reconstruído a partir dos tensionamentos de um presente vivo que redireciona o próprio olhar dos sujeitos. No processo formativo dos estudantes da educação do campo, essa questão é tratada com importância, pois a licenciatura assume o compromisso de produzir uma outra história com esses sujeitos. Afinal, o que seria a história para Benjamin 
senão o movimento contínuo do presente que nos tensiona e nos provoca a produzirmos estranhamentos a partir do encontro com tantas experiências possíveis?

O Caderno da Realidade como mediação que acolhe as memórias e oportuniza a narrativas passa a se constituir ainda como locus de registro das experiências comunitárias, de suas histórias e trajetórias, com destaque para os modos de vida dos campesinos em suas dimensões culturais, econômicas e sociais. Experiências que são sistematizadas pelos estudantes e que cunham as identidades individuais e coletivas das comunidades: "A Ufes me fez abrir a mente e descobrir que eu faço parte da minha comunidade. A maioria dos trabalhos de pesquisa tentei levar para a minha realidade. E a cada descoberta eu me via mais parte desse processo" (MARIA). Emerge-se, assim, o sentimento de pertença, o reconhecimento da integração do sujeito ao meio e o compromisso dele com este.

O caderno da realidade foi de grande importância, pois é ali que ficaram registradas todas as minhas pesquisas da comunidade [...], entrevistas que realizei com pessoas que já faleceram. Esse registro é único, tenho certeza de que ficou na história. Essas entrevistas eram gostosas de fazer, os idosos se sentiam importantes, pertencentes àquela determinada história (GERALDO).

No movimento dialógico da escuta e do registro das memórias das comunidades, produz-se também experiência formativa (JOSSO, 2004), individual e coletiva. Nessas histórias, estão as marcas de um processo impregnado de valorização dos sujeitos campesinos, de questionamentos das realidades e dos compromissos assumidos a partir da formação. A inserção comunitária e o compromisso social dos estudantes são provocações da formação por alternância e do movimento nacional da educação do campo, na utopia possível de uma outra escola, de outras pedagogias, de outra sociedade. Não obstante, as narrativas, à luz de Bertaux (2010) como práticas em situação, baseiam-se na ideia central de que, pelas práticas narradas, pode-se começar a compreender os contextos sociais nos quais elas se inscrevem. Assim, buscar experiências, registrá-las na escrita e anunciá-las na oralidade são movimentos rumo à compreensão contextual dessas experiências, não mais isoladas, mas relacionadas.

É nessa perspectiva que nos enredamos na terceira abordagem das narrativas dos estudantes: a formação profissional docente do campo: 
Nesta instituição, vi um campo de oportunidades, um universo aberto para o conhecimento, uma porta que abre caminhos brilhantes, caminho este que estou seguindo. Representa uma universidade renomada e respeitada dentro do estado. Representava para mim um sonho bom! [...] Foi difícil eu ir me acostumando, até hoje estou neste processo finalizando esses quatro anos de licenciatura com tantas certezas ou diria incertezas que ainda não temos sobre nosso trabalho como professor quando estivermos formados. Penso nisso!!! Pois será que algum dia terá concurso público para estes profissionais? Será que nós poderemos nos inscrever nos processos seletivos concorrendo com um professor formado em uma disciplina específica de igual por igual? Ser professor nesta atual sociedade a qual estamos vivendo de certa forma me deixa angustiada, já que a profissão passou a ser tão desvalorizada e nós recém-formados muitas barreiras e dificuldades vamos encontrar (MARISA).

Ao se aproximarem da finalização do curso, os estudantes narram ainda suas inquietações acerca do acesso ao mundo do trabalho, por meio da docência no campo. Cientes das condições de precarização que atravessam a profissionalização docente no que diz respeito aos locais de trabalho, à formação, à organização e ao ethos profissional, os sujeitos-narradores evocam suas memórias para pensarem os desafios futuros. Como interlocutores processuais das teorias que compõem a discussão da formação docente em interface às realidades de suas comunidades, as narrativas expressam preocupações legítimas e desafiam a universidade a abrir novas trincheiras de luta, entre essas o direito ao pleito público de acesso profissional às escolas do campo, por meio do reconhecimento do curso por parte das secretarias de educação que promovem os editais de contratação de professores.

As discussões trazidas por cada disciplina se tornaram muito importantes na minha formação e por quem fui me construindo, me tornando e me reconhecendo ao longo desses três anos e meio. Durante esse tempo, várias foram as dúvidas, os questionamentos as interrogações sobre minha existência, sobre minha fé, meu comportamento, minhas escolhas e principalmente sobre minha forma de ser/estar no mundo. As discussões sobre as relações étnico-raciais, relações de gênero e sobre as diversidades de gênero se tornaram as mais marcantes no decorrer desse processo, passei a entender, aceitar, questionar e me autoconhecer como sujeito de resistência. Por fim, considero esse curso como uma porta para minha liberdade, para o reconhecimento e aceitação da minha sexualidade, minha posição política e para o crescimento da minha formação profissional e pessoal (JOÃO).

Para além das questões objetivas da profissão docente, o estudante-narrador expressa a experiência formativa, o autoconhecimento, a dúvida propulsora dos questionamentos existenciais e as discussões provocadas pelo curso como 
reconhecimento da pluralidade humana. Dessa forma, a compreensão não dissociada da formação profissional e pessoal revela-se nas narrativas como uma das aprendizagens para o exercício da profissão docente no campo.

Outrossim, a formação política é também anunciada na voz e no registro do narrador como aprendizagem para a profissão professor do campo. Na esteira de Freire (1996), com vistas à formação que respeita a autonomia do educando, são produzidas aprendizagens pautadas na compreensão de que a Educação é uma forma de intervenção no mundo.

A própria expressão "mundo", no presente texto, assume uma conotação ampla. Chamamos a atenção para, assim como Walter Benjamin, pensarmos o mundo como o encontro com o outro, permeado pela experiência e pelos tensionamentos de tantos outros concretos e outros possíveis. Os Cadernos da Realidade evidenciam que o processo de educar ocorre numa via ampla, na qual os intercruzamentos de experiências renovam e reorientam a formação dos sujeitos que nesses se apresentam. As experiências históricas e existenciais de cada comunidade que constituem as trajetórias desses sujeitos os educam; porém o encontro com as experiências concretas e possíveis compartilhadas no coletivo - com seus contrastes, semelhanças e singularidades — somadas às possibilidades de ser e conhecer oferecidas pelo espaço universitário, promovem um movimento de (re)educar-se continuamente no intercâmbio de saberes e fazeres advindos dessa escuta dialógica promovida no encontro com tantos outros.

Afinal, o que seria ouvir o outro senão um exercício duplo de pensar o outro e, ao mesmo tempo, refletir a si mesmo como parte desse outro? Como Benjamin enuncia, ao se escutar e compartilhar experiências, unimos os sujeitos a partir de um laço de pertencimento. Fazemos parte da história do outro e ele da nossa, e no acolhimento pela escuta, nos tornamos corresponsáveis por uma história em comum iniciada nesse entrelaçamento. Pensar as possibilidades disso no campo educacional, além de necessário, pode ser extremamente fecundo, inclusive na dimensão ética da existência. Num mundo onde o individualismo se multiplica num tom ainda mais agressivo do que aquele já analisado por Benjamin, a construção de um envolvimento 
e de uma responsabilidade para com o outro (e sua história) pode possibilitar a constituição de cuidado pela escuta, de reafirmação da alteridade por tal via.

O processo de um movimento formativo que perpassa pelas ideias de Benjamin, aliás, pressupõe assumir as mudanças e contradições da realidade, e, para que de fato isso aconteça, é preciso abrir a possibilidade do espaço de ouvir o outro e como ele é atravessado por experiências diversas, pois “[...] para pensar a mudança e a contradição, o sujeito precisa incorporar as verdades de diferentes momentos, a riqueza de experiências que se realizam em condições diversas. O dialético, portanto, não pode deixar de ser um indivíduo capaz de ouvir o outro" (KONDER, 1999, p. 16). O trabalho com os cadernos da realidade, por tudo que analisamos até o momento, se apresenta como uma vivência formativa possível desse processo.

Por fim, mas não concluindo, compreendemos que as experiências expressas nas narrativas e também registradas na escrita dos Cadernos da Realidade potencializam aprendizagens que transcendem saberes e fazeres pragmáticos da docência no campo. As investigações produzidas no âmbito das comunidades, o olhar em retrocessos do percurso formativo na universidade $e$ as constantes problematizações, mobilizam um pensar crítico acerca dos desafios elencados pela educação do campo e requerem dos professores desse contexto saberes e fazeres atravessados pela perspectiva político-emancipatória.

Assim, os Cadernos da Realidade como guardiões da memória e das experiências vivas, forjam outros modos de produção do conhecimento ao protagonizarem as narrativas e provocarem os docentes a produzirem interlocuções teórico-práticas e metodológicas que rompam com as dualidades teoria e prática, universidade e comunidade, saber científico e senso comum. Como mediadores da aprendizagem dos estudantes, os Cadernos da Realidade são locus das experiências formativas, essas sistematizadas e registradas nas histórias dos estudantes e do curso, com todas as contradições que permeiam as ações humanas, tal como afirma a estudante Joelma, sujeito dessa pesquisa: "Como fruto de uma gestação de riscos, o Caderno da Realidade — memórias, afetos, conquistas e fracassos — expõe vitórias e vergonhas inconfessáveis, tudo irremediavelmente sedimentado como história”. 


\section{Considerações finais}

Compreendemos, ao longo das narrativas, que o processo formativo construído na alternância nos remete a pensar não somente através da história, mas dentro de uma multiplicidade de histórias vivas e encarnadas pelos sujeitos que criam e recriam a educação do campo. Reconhecemos desse modo, num exercício benjaminiano, que a formação de educadores ocorre, em especial, quando assumimonos como seres temporais, carregados do lastro do movimento da vida e das diversas temporalidades e materialidades que a animam e lhe dão fôlego, deixando assim se revelar em sua nudez os paradoxos e as contradições que caracterizam o universo humano. As experiências dos sujeitos nos apontam que não existe o "homem do campo" enquanto estrutura singular e universal, mas sujeitos adstritos a sua concretude histórica e cultural, criando um complexo e contraditório mosaico que expressa as contradições da realidade do universo rural no Brasil.

Como pensar a formação dos professores que atuam ou atuarão na educação do campo sem nos atermos a tal questão, que é de grande importância na conjuntura aqui instaurada? Ao não o exercitarmos, corremos o risco de assumir uma idealização desses sujeitos que pode ser profundamente nociva. Isso porque, ao adotarmos um modelo pré-concebido de "homem do campo", caímos no risco de ignorar que as mulheres, homens, jovens e crianças do campo, em sua pluralidade políticoontológica, são sujeitos históricos que, através dos processos de lutas e resistências, reelaboram continuadamente estratégias de (sobre)vivências e (re)invenção de suas próprias trajetórias singulares que, a todo momento, estão dialeticamente conectadas à história de comunidades, famílias e movimentos sociais. Para tanto, é primordial construirmos com os sujeitos camponeses outras racionalidades que nos provoquem a produzir e desvelar processos formativos que levem em conta esse atravessamento pela e com a experiência do outro. A ideia de razão, portanto, deve ser constantemente revisada nesse processo, tal como Benjamin incansavelmente fez em seu trabalho à medida que:

Benjamin não era um irracionalista; não é casual, contudo, que alguns críticos tenham enxergado elementos de irracionalismo no seu pensamento. Ele se insurgiu, muitas vezes, contra tudo aquilo que Ihe parecia constituir uma formalização 
"congeladora" da razão, empenhado no desenvolvimento de uma razão capaz de se abrir constantemente para o "novo", capaz de se submeter a uma permanente revisão autocrítica, capaz de se enriquecer a cada instante numa ligação profunda e ininterrupta com a vida. E talvez seja esse o aspecto filosoficamente mais instigante do legado de Benjamin: sua fascinante aventura espiritual na busca apaixonada de um novo conceito de razão (KONDER, 1999, p. 120).

É importante ressaltar ainda que pensar sob a ótica benjaminiana pressupõe não aceitar o preenchimento absoluto de um sentido. Antes, coloca-nos uma hermenêutica do inacabamento, no intercâmbio do e com o outro como um lugar de produção contínua da nossa própria formação, que deve estar conectada à produção da vida e da história. Nesse aspecto, a tese de número 06 de Benjamin trata do perigo de se olhar para a história e para as memórias dos sujeitos como algo estático, acabado, e da necessidade de seguirmos o clarear de um relampejo, percebendo o conhecimento como o lugar de renovação constante de esperanças que nascem a partir da luta e do perigo. O inconformismo é um lugar político-epistemológico inerente ao pensamento de Benjamin, conforme apresentado na tese 06:

Articular historicamente o passado não significa conhecê-lo "como ele de fato foi". Significa apropriar-se de uma reminiscência, tal como ela relampeja no momento de um perigo. Cabe ao materialismo histórico fixar uma imagem do passado, como ela se apresenta, no momento do perigo, ao sujeito histórico, sem que ele tenha consciência disso. O perigo ameaça tanto a existência da tradição como os que a recebem. Para ambos, o perigo é o mesmo: entregar-se às classes dominantes, como seu instrumento. Em cada época, é preciso arrancar a tradição ao conformismo, que quer apoderar-se dela. Pois o Messias não vem apenas como salvador; ele vem também como o vencedor do Anticristo. O dom de despertar no passado as centelhas da esperança é privilégio exclusivo do historiador convencido de que também os mortos não estarão em segurança se o inimigo vencer. E esse inimigo não tem cessado de vencer (BENJAMIN, 1996, p. 224).

Essas reflexões do autor ecoam de modo bastante especial na educação do campo, pois esta abriga sujeitos que, historicamente, tiveram seus direitos negados e vivenciam, em sua maioria, profundos processos de exclusão que não os permitiram chegar aos espaços das universidades ou, em muitos casos, tardiamente ao espaço da escola da Educação Básica. Demarcar as narrativas e trajetórias formativas desses sujeitos é, portanto, demarcar um lugar político de luta numa sociedade na qual as forças conservadoras buscam deslegitimar os espaços de conquista e afirmação de tais sujeitos. Destacamos ainda que o senso de pertencimento nos une a um processo 
formativo que abre a possibilidade de os sujeitos narrarem a si mesmos, a partir daquilo que atentamente escutaram de outrem. Isso tem possibilitado, no diálogo promovido pelos Cadernos da Realidade, um encontro político-existencial que se desvela a partir da palavra escutada e (re)transmitida. A palavra e a escuta assumem aqui, portanto, simultaneamente, um espaço epistemológico, político e educativo.

As marcas biográficas presentes nos Cadernos da Realidade expressam claramente como esse movimento dialético e íntimo entre as histórias de vida dos sujeitos em formação e a história e realidade social e cultural de suas comunidades criam movimentos instituintes que apontam um processo formativo que é acolhido como aceno e dinâmico da própria produção da vida. O campo é vida quando a produção de conhecimento sobre o campo é feita pelos sujeitos do campo e no campo. Eis um pressuposto fundamental da alternância importante de ser retomado continuamente, pois voltar às origens não representa repetir, mas abrir possibilidades de emancipação e reinvenção a partir do que foi. Numa acepção inspirada em Benjamin, podemos enfatizar que a história é um movimento contínuo de recriação da experiência humana.

\section{Referências}

ANTUNES-ROCHA, M. I.; PERNAMBUCO, M. M. C.; PAIVA, I. A.; REGO, M. C. F. D. Formação e trabalho docente na escola do campo: protagonismo e identidades em construção. In: MOLINA, M. (Org.). Educaşão do Campo e Pesquisa II: Questões para Reflexão. Brasília: MDA/MEC, 2010. p. 65-74.

BENJAMIN, W. Magia e técnica, arte e política: ensaios sobre literatura e história da cultura. 2. ed. São Paulo: Editora Brasiliense, 1996. (Obras escolhidas, v. I).

BERTAUX, D. Narrativas de Vida: A Pesquisa e Seus Métodos. São Paulo: Paulus, 2010.

FREIRE, P. Pedagogia da Autonomia. Saberes necessários à prática educativa. São Paulo: Paz e Terra, 1996.

GAGNEBIN, J. M. História e narração em Walter Benjamin. São Paulo: Perspectiva, 1999.

GERKE DE JESUS, J. Formação do Professores na Pedagogia da Alternância: Saberes e fazeres do campo. Vitória/ES: GM, 2011.

GIMONET, J.C. Praticar e compreender a pedagogia da alternância dos CEFFAS. Petrópolis: Vozes, 2007. 
HELENA, L. Um sultão no reino das coisas. Revista Alea, Rio de Janeiro, v. 5, n. 1, p. 13-27, 2003. Disponível em http://www.scielo.br/scielo.php?script=sci_arttext\&pid=S151706X2003000100002. Acesso em: 15 ago. 2019.

JOSSO, M. C. Experiências de Vida e Formação. São Paulo: Cortez, 2004.

KONDER, L. Walter Benjamin: o marxismo da melancolia. 3. ed. Rio de Janeiro: Civilização Brasileira, 1999.

RIAVIZ, V. N. Freud e Benjamin: uma arqueologia da história. Revista Grifos, Chapecó, n. 10, p. 29-38, jun. 2001.

UNIVERSIDADE FEDERAL DO ESPÍRITO SANTO (UFES). Projeto pedagógico do curso de licenciatura plena em educação do campo. Vitória: Centro de Educação, 2018. Recuperado de: http://www.ce.ufes.br/sites/ce.ufes.br/files/field/anexo/PPC_LEC_0.pdf. Acesso em: 15 ago. 2019.

ZAMBERLAN, S. O Caderno da Realidade. CFR/MEPES. Documento não publicado. 1989.

ZAMBERLAN, S. Entrevista concedida a Janinha Gerke. Anchieta/ES, 7 ago. 2019.

RECEBIDO: $30 / 05 / 2020$

APROVADO: 20/07/2021
RECEIVED: 05/30/2020

APPROVED: 07/20/2021
RECIBIDO: 30/05/2020

APROBADO: 20/07/2021 